See discussions, stats, and author profiles for this publication at: https://www.researchgate.net/publication/296635708

\title{
"Influence of storage conditions on phenolic compounds stability, antioxidant capacity and colour of freeze-dried encapsulated red wine"
}

Article in LWT- Food Science and Technology · July 2016

DOI: 10.1016/.j.lwt.2016.02.038

CITATIONS

26

4 authors:

Diego Rocha-Parra

National Scientific and Technical Research Council

7 PUBLICATIONS 72 CITATIONS

SEE PROFILE

María Clara Zamora

Pontifical Catholic University of Argentina

59 PUBLICATIONS 1,143 CITATIONS

SEE PROFILE
585

Maria Cecilia Lanari

argentinean national research council CONICET

34 PUBLICATIONS 1,346 CITATIONS

SEE PROFILE

Jorge Chirife

Pontifical Catholic University of Argentina

334 PUBlications 7,767 CITATIONS

SEE PROFILE

Some of the authors of this publication are also working on these related projects:

Project Impacto del valor hedónico y el valor de incentivo en las preferencias por sabores amargos View project

Propiedes funcionales de la yerba mate y posibles aplicaciones en la industria alimentaria View project 


\title{
"Influence of storage conditions on phenolic compounds stability, antioxidant capacity and colour of freeze-dried encapsulated red wine"
}

\author{
Diego Fernando Rocha-Parra a, b, *, María Cecilia Lanari b, c, María Clara Zamora a, b, \\ Jorge Chirife ${ }^{a}$ \\ ${ }^{a}$ Facultad de Ciencias Agrarias, Pontificia Universidad Católica Argentina (UCA), R. Freire 183, Buenos Aires, 1426AVC, Argentina \\ ${ }^{\mathrm{b}}$ Members of Consejo Nacional de Investigaciones Científicas y Técnicas (CONICET), Buenos Aires, Argentina

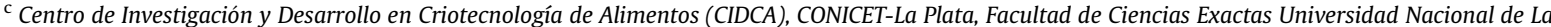 \\ Plata (UNLP), Calle 47 y $116 \mathrm{~S} / \mathrm{N}^{\circ}$, La Plata B1900AJJ, Buenos Aires, Argentina
}

\section{A R T I C L E I N F O}

\section{Article history:}

Received 18 December 2015

Received in revised form

11 February 2016

Accepted 18 February 2016

Available online 24 February 2016

\section{Keywords:}

Freeze-drying

Polyphenols

Red wine

Water activity

Antioxidant capacity

\begin{abstract}
A B S T R A C T
A concentration of $9 \%(w / w)$ maltodextrin (DE 10) and gum arabic was added to red wine C. sauvignon and freeze dried to obtain a dealcoholized wine powder having a polyphenols concentration 7.1 times higher than in liquid red wine. Malvidin 3-G and total anthocyanins were the phenolics showing greater losses during storage. Moreover, an increase of water activity from 0.11 to 0.58 greatly enhanced the losses. The decrease in malvidin 3-G content was associated with the decrease on redness (colour parameter $\mathrm{a}^{*}$ ) of wine powder. Gallic acid was the most stable phenolic and its content remained constant during storage at all water activity levels under investigation. Contents of epicatechine, catechine, caffeic acid and resveratrol remained constant at $\mathrm{a}_{\mathrm{w}}=0.11$, although at $\mathrm{a}_{\mathrm{w}}=0.33$ catechine and epicatechine suffered important losses. Results indicated that water activity was a key factor affecting phenolics stability during storage.

Antioxidant activity of the wine powder remained constant over 145 days at accelerated storage conditions.
\end{abstract}

๑) 2016 Elsevier Ltd. All rights reserved.

\section{Introduction}

Epidemiological evidence indicates that moderate consumption of red wine reduces the incidences of coronary heart disease, atherosclerosis and platelet aggregation (Li et al., 2009; Tedesco et al., 2000). Wine is an important component in Mediterranean dietary tradition because it is very rich in antioxidant compounds. This protection is mainly attributed to the phenolic components of wines, which are particularly abundant in the red wine.

The polyphenolic contents of wine consist in two classes of components (flavonoids and non-flavonoids) and depend on a variety of factors such as the grape variety, vineyard location, climate, soil type, harvesting time, production process, etc. Although the mechanisms of action are yet to be fully understood, it is generally

\footnotetext{
* Corresponding author. Facultad de Ciencias Agrarias, Pontificia Universidad Católica Argentina (UCA), R. Freire 183, Buenos Aires, 1426AVC, Argentina.

E-mail address: diegofer2484@gmail.com (D.F. Rocha-Parra).
}

accepted that phenolic compounds behave as antioxidants. They can protect cholesterol in the low-density lipoprotein (LDL) from oxidation (Brouillard et al., 1997). However, there are some clear drawbacks in wine consumption associated with the ingestion of alcohol: a) consumption must be moderate ( $1-2$ glasses per day) in order to avoid alcohol related diseases, and b) many people, either by ethnical, social or religious reasons do not consume wine (Midgley, 1971). This was resolved by Sanchez, Baeza, Galmarini, Zamora, and Chirife (2013), who reported preliminary results on the freeze drying encapsulation of red wine with maltodextrin $(20 \%$ $\mathrm{w} / \mathrm{w}$ ) obtaining an alcohol-free powder. Water and almost all alcohol from wine were removed during freeze drying and the use of maltodextrin as a drying aid led to an amorphous, glassy microstructure in which the wine phenolics - as well as other components of dry wine extract (glycerol, sugars, organic acids, salts, etc) were encapsulated.

Munin and Edwards-Lévy (2011) noted the lack of long term storage stability of polyphenols since are usually very sensitive to light and heat, and encapsulation appears to be a promising 
approach to gain stability. Encapsulation by freeze-drying can be used in the food industry to protect the nutraceuticals by preventing the oxidation, reducing the losses of volatile substances, making handling easier, facilitating or making more difficult the premature interaction with other ingredients, and regulating food bioactive content during its industrialization processes (Deyse Gurak, Correa, \& Rocha-Leão, 2013). Numerous wall materials or encapsulating agents are available for use in food. The ideal encapsulant should have film-forming properties, have emulsifying properties, be biodegradable, be resistant to the gastrointestinal tract, have low viscosity at high solids contents, exhibit low hygroscopicity and have a low cost. The hydrocolloids, such as maltodextrin and gum arabic, are among the wall materials, most commonly used in the fruit juice encapsulation process using spray drying or freeze drying techniques. These carrier agents, and also blends of maltodextrin and gum arabic also protect adequately the fruit's bioactive compounds (i.e. anthocyanins) from oxidation (Ferrari, Marconi Germer, Alvim, \& de Aguirre, 2013; Tonon, Brabet, \& Hubinger, 2010). Recently, Mahdavi, Jafari, Ghorbani, and Assadpoor (2014) reviewed microencapsulation of anthocyanins with different biopolymers through spray drying to develop natural colorant pigments which possess high stability, solubility, and dispersibility. They noted that biopolymer used for microencapsulation by spray drying is very important for encapsulation efficiency and microcapsule stability and indicated that typical biopolymers generally suitable for spray-drying microencapsulation of anthocyanins include gum arabic and maltodextrin, among others.

Besides of fruit juices, drying encapsulation may be also used to produce powdered pigments obtaines from winewastes products, although this requires a previous solvent extraction of polyphenols. De Souza, Thomazini, Balieiro, and Favaro-Trindade (2015) produced and evaluated powdered pigments obtained from vinification by-products of Bordo red grapes (Vitis labrusca). The concentrated extract obtained from the by-products was spray dried (and also freeze-dried) under different conditions of inlet air temperatures (130-170 ${ }^{\circ} \mathrm{C}$ ) and carrier (maltodextrin) concentration (10-30\%). Galmarini et al. (2013) reported storage stability of several phenolics in a red wine powder encapsulated (freeze drying) in maltodextrin $(20 \% \mathrm{w} / \mathrm{w})$.

The objective of the present work was to study the stability of red wine phenolics encapsulated in $9 \%(\mathrm{w} / \mathrm{w})$ of maltodextrin and gum arabic mixture. The total concentration of encapsulating agents added to red wine was considerably less than previously used by Sanchez, Baeza, Galmarini, Zamora, and Chirife (2013) who added $20 \%(\mathrm{w} / \mathrm{w})$ of maltodextrin alone as carrier material. A lower addition of encapsulants (while protecting the bioactive compounds) bring about benefits for the development of healthy drink powders because increasing concentration of wine polyphenols, and improved sensory profile as showed recently by Parra, Galmarini, Chirife, and Zamora (2015). Present study included the effect of water activity $\left(a_{w}\right)$ on the content of various phenolics, colour and antioxidant capacity of the encapsulated red wine powder (EWP) stored at $38{ }^{\circ} \mathrm{C}$ during several months.

\section{Materials and methods}

\subsection{Materials}

Wine used was a commercial Cabernet Sauvignon, "Postales del Fin del Mundo" from Neuquén province, Argentina. Its alcohol content was $13.7 \%(\mathrm{v} / \mathrm{v})$ and $\mathrm{pH}$ 3.6. Total polyphenol content was $2230 \pm 160 \mathrm{mg}$ GAE/L as determined Folin-Ciocalteau method (see below). Carbohydrates used for encapsulation were a mixture of Maltodextrin (Dextrose Equivalent $10\left(\mathrm{MD}_{10}\right)$ from Productos de
Maíz, S.A., Argentina) and gum arabic (from Gelfix, Buenos Aires, Argentina).

Salts (reagent grade) used for relative humidity (RH \%) control were: Potassium acetate $\left(\mathrm{CH}_{3} \mathrm{COOK}\right)$, magnesium chloride $\left(\mathrm{MgCl}_{2}\right)$, potassium carbonate $\left(\mathrm{K}_{2} \mathrm{CO}_{3}\right)$, and sodium bromide $(\mathrm{NaBr})$; they were purchased from Biopack, Argentina.

The Folin-Ciocalteau reagent was obtained from Merck KgaA Darmstadt, Germany. The 2,2-diphenyl-1-picrylhydrazyl free radical $\left(\mathrm{DPPH}^{*}\right), \beta$-Carotene, Linolenic acid $\geq 99 \%$, TWEEN ${ }^{\circledR} 20$ (Polyethylene glycol sorbitan monolaurate) and chloroform used for antioxidant quantification were purchased from Sigma Aldrich, St. Louis, USA. HPLC-grade reagents malvidin-3-glucoside chloride (malvidin 3-G), catechine, epicatechine, caffeic acid, gallic acid, and resveratrol (all of them $>95 \%$ purity) were purchased from Sigma Aldrich, St. Louis, USA; Solvents used were: acetonitrile (ACN), formic acid (FA), methanol (MOH), and Hydrochloric acid (HCL). All were obtained from J.T. Baker, USA, Cicarelli, Argentina and Carlo Herba, Spain. Double-distilled water (HPLC grade) was elaborated at a facility of the University.

\subsection{Encapsulation procedure}

A blend (65:35) of $\mathrm{MD}_{10}$ and gum arabic was dissolved in red wine at a ratio of $9 \%$ concentration (total weight basis). The mixture was then freeze-dried to encapsulate the dry extract of wine (containing its polyphenols). The wine with carrier agents was poured into an aluminium tray (depth of sample, $1 \mathrm{~cm}$ ) and frozen at $-20{ }^{\circ} \mathrm{C}$ during $24 \mathrm{~h}$. The freeze-dried process was performed using a laboratory-scale FIC-LI-I-E300-CRT freeze dryer (Rificor, Buenos Aires, Argentina) operated with a freezing plate and condenser at $-40^{\circ} \mathrm{C}$ and a vacuum of $100 \mu \mathrm{m} \mathrm{Hg}$ during $40 \mathrm{~h}$ and at room temperature. Freeze dried samples had a water activity $\left(\mathrm{a}_{\mathrm{w}}\right)$ of 0.11 ; it was measured using a dew point hygrometer "Aqualab" (Decagon Devices USA). Ethanol from wine as well as water were eliminated during freeze-drying, leading to a dealcoholized EWP. The freeze-dried product - a porous cake of glassy aspect -was milled in a domestic grain coffee grinder leading to a free-flowing powder which was stored in hermetic, dark glass flasks for further analysis.

\subsection{Storage conditions}

EWP in small opaque glass flasks was stored in a constant temperature oven kept at $38^{\circ} \mathrm{C}$ in one or the other of the following conditions, a) in hermetically sealed flasks in order to preserve its initial moisture condition $\left(a_{w}=0.11\right)$; $\left.b\right)$ in open flasks placed over a saturated solution of $\mathrm{MgCl}$ which provided a constant relative humidity of $33 \%$, and c) in open flasks placed over a saturated solution of $\mathrm{NaBr}$ which provided a constant relative humidity of $58 \%$. Temperature $38{ }^{\circ} \mathrm{C}$ is representative of accelerated shelf life studies; thus storing at $38{ }^{\circ} \mathrm{C}$ and water activity 0.33 are called hereinafter "accelerated storage conditions".

Samples of all systems were periodically removed from storage and analyzed during 145 days.

\subsection{Adsorption isotherm}

Equilibrium moisture contents of wine powder were determined using the well known static gravimetric method (Iglesias \& Chirife, 1982). Samples of EWP were placed in desiccators containing four different saturated salt solutions which provided the following relative humidities), $\mathrm{CH}_{3} \mathrm{COOK}(22 \% \mathrm{RH}), \mathrm{MgCl}_{2}$ (33\%RH)), $\mathrm{K}_{2} \mathrm{CO}_{3}(\mathrm{RH} 43 \%)$ and $\mathrm{NaBr}(58 \% \mathrm{RH})$. Desiccators were placed in an oven at $38^{\circ} \mathrm{C}$ and after an equilibrium time of three weeks moisture content of samples was determined gravimetrically using $2 \mathrm{~g}$ 

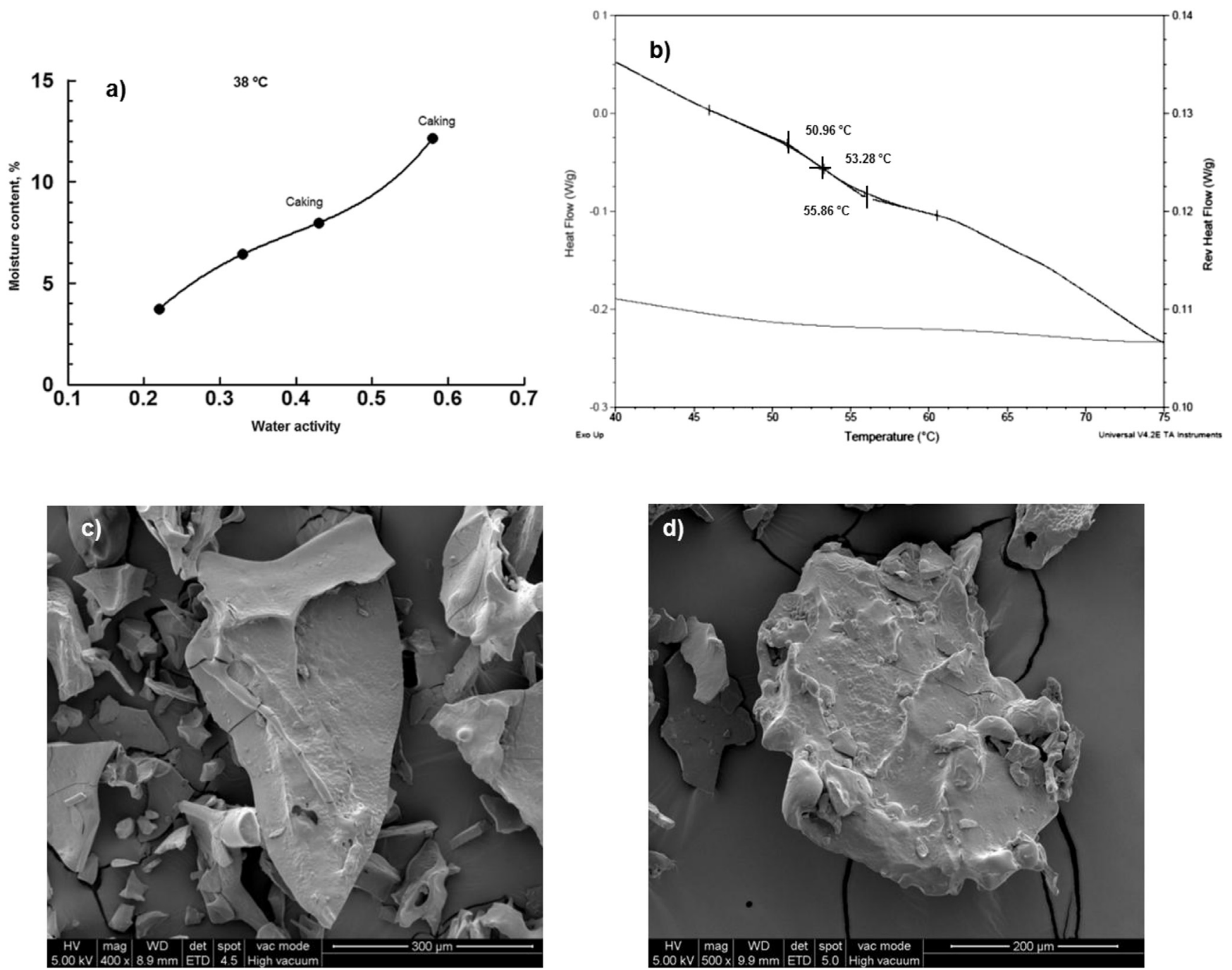

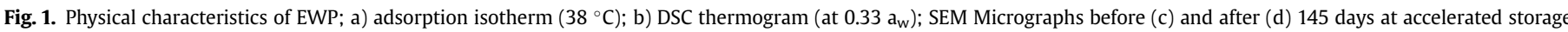
conditions.

sample dried in an air-circulating oven at $90{ }^{\circ} \mathrm{C}$ during $15 \mathrm{~h}$.

\subsection{Differential scanning calorimetry (DSC)}

The glass transition temperature ( $\mathrm{Tg}$ ) of the EWP was determined using a differential scanning calorimeter (model DSC 2010, TA Instruments, New Castle, DE, USA). Approximately 4-5 mg of powder equilibrated with $\mathrm{MgCl}_{2}$ saturated solution (33\% $\mathrm{RH}$ ) was placed into aluminium pans $(20 \mu \mathrm{l})$. The equipment was calibrated with sapphire $\left(600^{\circ} \mathrm{C}\right)$. The samples were scanned from -30 to $100^{\circ} \mathrm{C}$ at a rate of $10^{\circ} \mathrm{C} / \mathrm{min}$. An empty pan was used as a reference. The onset values for glass transition temperature of the samples were calculated using the software Universal Analysis (TA instruments).

\subsection{Scanning electron microscopy (SEM)}

Scanning Electron Microscopy, morphological analysis was performed by SEM using a FEI, Quanta 200 microscope (Netherlands). The samples were placed in a carbon support and coated with a layer of gold $(40-50 \mathrm{~nm})$ and examined using an acceleration voltage of $5 \mathrm{kV}$. Three samples of EWP were observed: powder before and after 145 days at accelerated storage conditions and powder after storage at $38^{\circ} \mathrm{C}$ and $0.58 \mathrm{a}_{\mathrm{w}}$.

\subsection{Colour}

Colour measurements was analyzed using a Minolta Spectrophotometer CM-600d (Konica Minolta Observer), with D65 illuminant and an observer angle of $2^{\circ}$. The colour measurement was obtained by placing samples of EWP in plastic white containers. CIELab parameters (CIE 1976, $L^{*} a^{*} b^{*}$ ) were $L^{*}$ for lightness, $a^{*}$ for redness and $\mathrm{b}^{*}$ for yellowness.

\subsection{HPLC analysis of polyphenols}

Samples were prepared by weighting $60.0 \pm 0.5 \mathrm{mg}$ of EWP which was dissolved in $1.5 \mathrm{ml}$ of solvent composed of a mixture of $\mathrm{H}_{2} \mathrm{O} / \mathrm{MOH} / \mathrm{HCl}$ (89/10/1) (Souquet, Veran, Mané, \& Cheynier, 2006). Prior to injection they were filtered through a Whatman PTFE syringe filter (diameter $=13 \mathrm{~mm}$, porosity $=0.45 \mu \mathrm{m}$ ). The injection volume was $20 \mu \mathrm{l}$.

HPLC analysis was carried out in a 1200 series HPLC instrument (Agilent Technologies, Waldbronn, Germany) equipped with a vacuum degasser, a quaternary pump, an autosampler and a thermostated column compartment. 

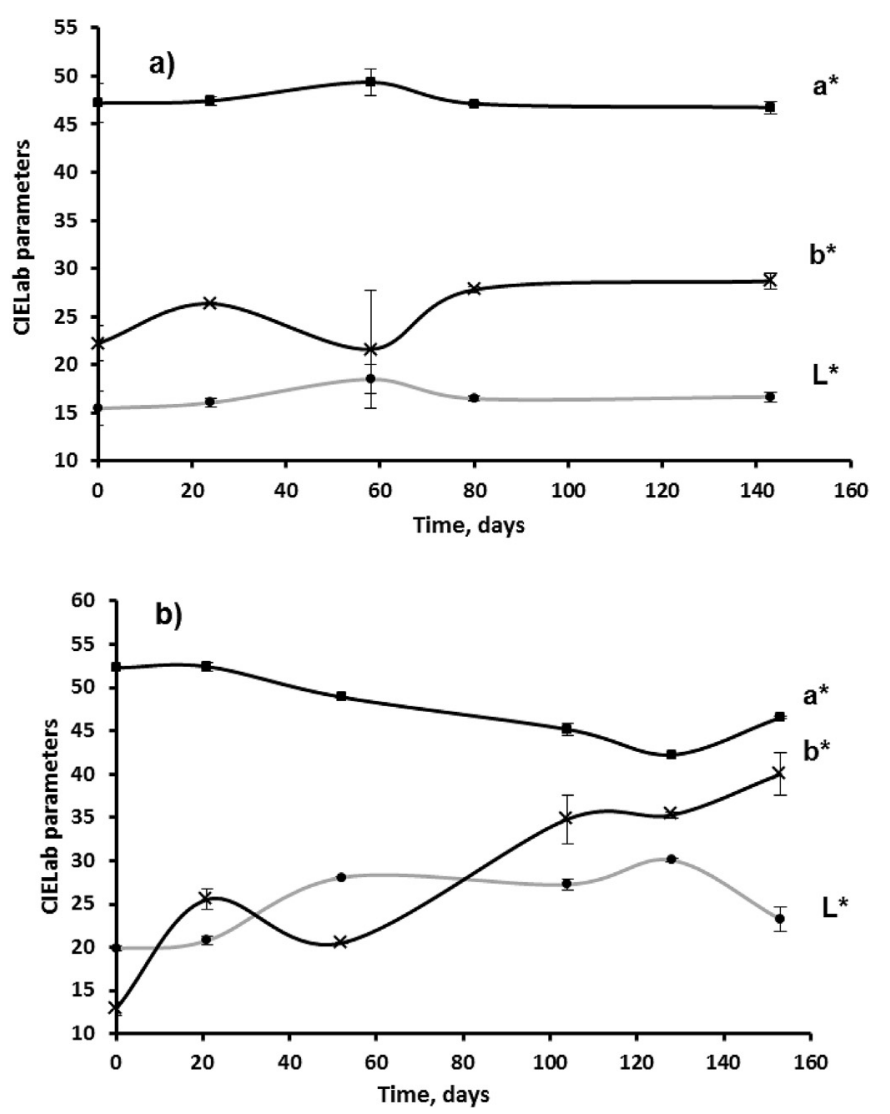

Fig. 2. Evolution of colour parameters $\left(a^{*}, b^{*}, L^{*}\right)$ for EWP stored at $38{ }^{\circ} \mathrm{C}$ up to 145 days: a) $0.11 \mathrm{a}_{\mathrm{w}}$; b) $0.33 \mathrm{a}_{\mathrm{w}}$ - In many cases SD bars overlap with data points.

Separation was achieved on a reverse phase using a size $150 \times 4.60 \mathrm{~mm}$ column size, Phenomenex Gemini $5 \mu \mathrm{C} 18,110{ }^{\circ} \mathrm{A}$. The column's temperature was maintained at $30^{\circ} \mathrm{C}$. Detection was performed using a diode array detector attached to a computer (HP Chemstation).

Two solvents were used during the analysis. Solvent A composed of distilled water/formic acid (95/5) and solvent B consisting of $\mathrm{ACN} / \mathrm{H}_{2} \mathrm{O} / \mathrm{FA}(80: 15: 5)$. A constant flow of $1 \mathrm{ml} / \mathrm{min}$ was applied with a linear gradient elution profile. The following proportions of solvent B were used following Galmarini et al. (2013) method, with some modifications: $0-3 \mathrm{~min}, 3 \%$; 3-5 $\mathrm{min}, 7 \%$; 5-10 min, 10\%; 10-12 min, 14\%; 12-20 min, 15\%; 20-23 min, 20\%; 23-32 min, 25\%; 32-34 min, 40\%; 34-39 min, 40\%; 39-41 min, 20\%; and 41-45 min, 3\%. Malvidin 3-G, catechine, epicatechine, caffeic acid, gallic acid and resveratrol were identified according to their retention time and spectral properties. Absorption wavelengths $(\lambda)$ at which each analyte was measured, were: $280 \mathrm{~nm}$ (catechine, epicatechine and gallic acid); $320 \mathrm{~nm}$ (caffeic acid and resveratrol) and $520 \mathrm{~nm}$ (malvidin 3-G). Quantification was done by external standard curves of authentic standards of each compound. The compounds were expressed as mg compound/100 $\mathrm{g}$ powder. Total anthocyanins were also analyzed by absorption at $520 \mathrm{~nm}$ and expressed as $\mathrm{mg}$ malvidin3-G equivalent/100 g powder.

\subsection{Total polyphenols}

Total polyphenols of red wine and EWP were determined by the Folin- Ciocalteau method (Camussoni \& Carnevali, 2004). Concentrations were expressed as milligrams gallic acid equivalent/
$100 \mathrm{~g}$ powder. EWP was dissolved in water $(1 \mathrm{~g}$ of powder in $8 \mathrm{~g}$ of water); then absorbance at $765 \mathrm{~nm}$ was measured and polyphenol concentrations of samples derived from a standard curve of gallic acid.

\subsection{Antioxidant capacity}

Changes in the antioxidant capacity along storage of the EWP was analyzed using two independent methods: free radical scavenging capacity of the $\mathrm{DPPH}^{*}$ (2,2-diphenyl-1-picryl- hydrazyl) (Stratil, Klejdus, \& Kuban, 2006) and B-Carotene/linoleic system (Lu \& Yeap Foo, 2000). For both methods $1 \mathrm{~g}$ of freeze dried powder was dissolved in $8 \mathrm{ml}$ of distilled water. Five dilutions were done in water in order to obtain solutions of EWP within the desired range of linearity of both methods.

\subsection{1. $D P P H^{*}$}

An aliquot of $100 \mu \mathrm{l}$ of EWP dissolved was mixed with $3.9 \mathrm{ml}$ of $\mathrm{DPPH}^{*}$ ethanol solution (25 mg DPPH*/1). Absorbance was determined at $517 \mathrm{~nm}$ after $60 \mathrm{~min}$ in darkness. Antioxidant activity was expressed as $\mathrm{mM}$ of gallic acid equivalents necessary to inhibit $50 \%$ of $\mathrm{DPPH}^{*}(\mathrm{EC} 50)$.

\subsection{2. $\beta$-Carotene/linoleic acid assay}

One millilitre of a solution of $\beta$-carotene in chloroform $(3.34 \mathrm{mg} /$ $\mathrm{ml}$ ) was pipetted into a flask containing $40 \mathrm{mg}$ linoleic acid and $400 \mathrm{mg}$ Tween 20 . The chloroform was removed by rotary evaporation at $40{ }^{\circ} \mathrm{C}$ for $5 \mathrm{~min}$ and, to the residue, $100 \mathrm{ml}$ of distilled water was added slowly with vigorous agitation, to form an emulsion. A $5 \mathrm{ml}$ aliquot of the emulsion was added to a tube containing $0.2 \mathrm{ml}$ of EWP dissolved and the absorbance was measured at $470 \mathrm{~nm}$, immediately, against a blank, consisting of the emulsion without b-carotene. The tubes were placed in a water bath at $40{ }^{\circ} \mathrm{C}$ and the absorbance measurements were made again at $120 \mathrm{~min}$.

The result was expressed as $\beta$-carotene inhibition of oxidation Index (AI \%).

\subsection{Data analysis}

All experiments were conducted in triplicate and the results were analyzed by one-way analysis of variance (ANOVA) test using Infostat v.2013 (Universidad Nacional de Córdoba, Argentina). Means comparisons among storage time were carried out by Tukey test at $\mathrm{P}<0.05$.

\section{Results and discussion}

The EWP obtained after freeze-drying was a free-flowing powder having $\mathrm{a}_{\mathrm{w}}=0.11$. Total polyphenol content was $1583 \pm 98 \mathrm{mg}$ $\mathrm{GAE} / 100 \mathrm{~g}$ powder which is 7.1 times higher than in liquid wine.

Fig. 1 shows (a) adsorption isotherm of EWP at $38{ }^{\circ} \mathrm{C}$ for a selected range of water activity (0.22-0.58). After an equilibrium time of three weeks, powder caking was observed at $a_{w}=0.43$ and 0.58 , but not at $\mathrm{a}_{\mathrm{w}}=0,33$ and below. This behaviour may be explained considering that physical changes in an amorphous matrix are time dependent being a function of $\left(\mathrm{T}-\mathrm{T}_{\mathrm{g}}\right)$, where $\mathrm{T}$ is the storage temperature and $\mathrm{T}_{\mathrm{g}}$ is the glass transition temperature (Roos \& Karel, 1991). Fig. 1. (b) shows the DSC thermogram at water activity of 0.33 ; a glass transition seems to be apparent in the thermogram. Furthermore, the onset, midpoint and end point glass transition temperature are indicated (Roos, 1995). The onset glass transition temperature $\left(50.96{ }^{\circ} \mathrm{C}\right)$ was taken as representative of the glass transition temperature of EWP at $\mathrm{a}_{\mathrm{w}}=0.33$. Since this value is higher than storage temperature $\left(38^{\circ} \mathrm{C}\right)$, the absence of 

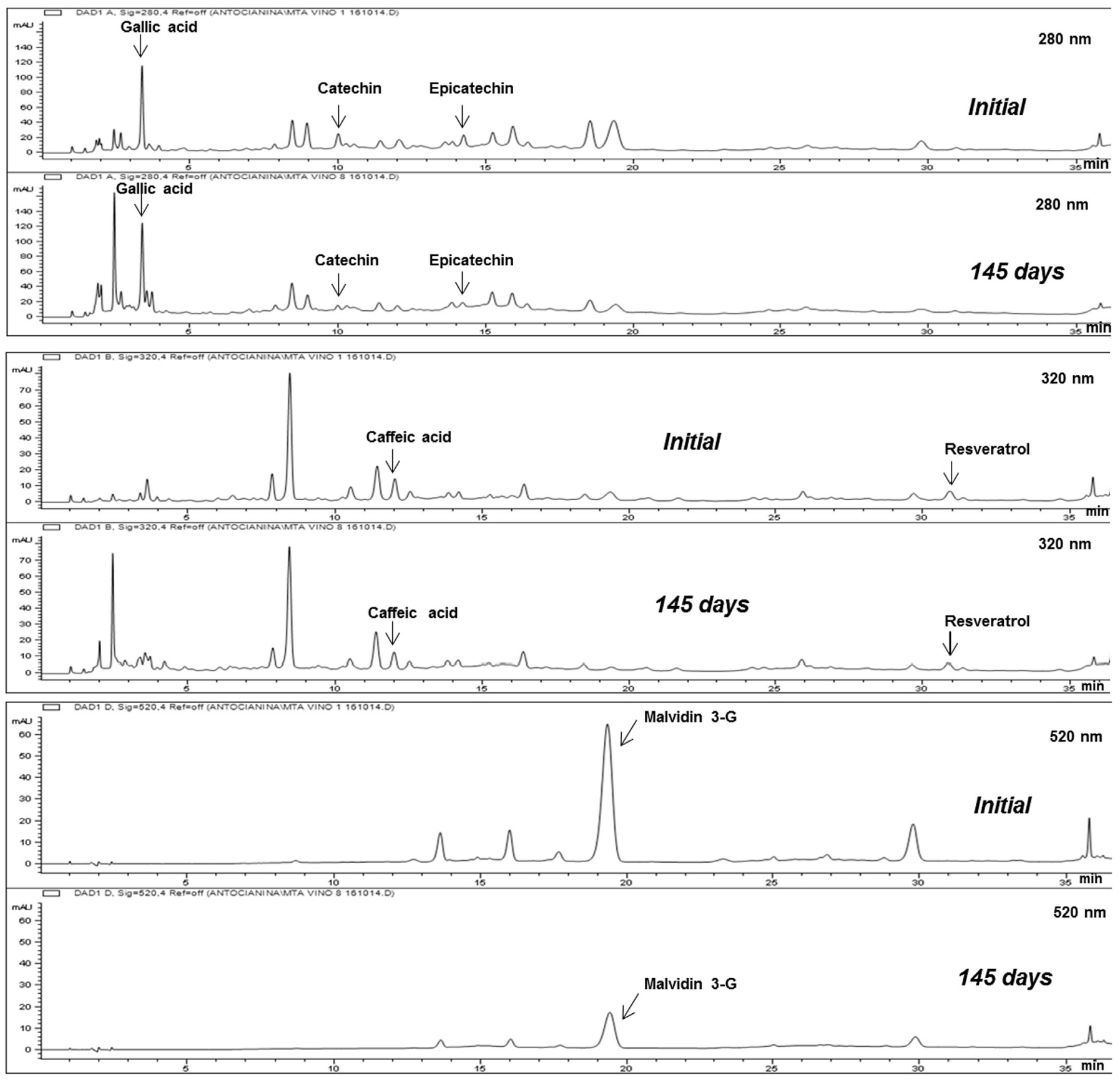

Fig. 3. Comparison of HPLC chromatogram of EWP before and after 145 days at accelerated storage conditions - Selected phenolics peaks are indicated.

caking at $\mathrm{a}_{\mathrm{w}}=0,33$ and below (as observed in the isotherm) may be attributed to the presence of a glassy state (Roos \& Karel, 1991). Fig. 1 (c,d) shows micrographs (scanning electron microscope) of EWP before and after storage at $38^{\circ} \mathrm{C}$ and $\mathrm{a}_{\mathrm{w}}=0.33$. The powder (c) shows irregular plate shaped particles of different sizes because they were ground after freeze drying. Similar results were reported by Deyse Gurak et al. (2013) for grape juice freeze dried encapsulated with maltodextrin and gum arabic. After 4.5 months of storage at $38{ }^{\circ} \mathrm{C}$ (d) some shrivelling of the surfaces plate shaped particles is noted.

Fig. 2 shows the changes in all colour parameters: $a^{*}$ (redness), $\mathrm{b}^{*}$ (yellowness), and $\mathrm{L}^{*}$ (lightness), values for EWP stored at $38{ }^{\circ} \mathrm{C}$ and two different water activities (0.11 and 0.33 ) over 145 days storage. Overall, it can be observed that at $\mathrm{a}_{\mathrm{w}}=0.11$ all colour parameters remained approximately constant and this was confirmed by an ANOVA test performed over the data ( $p \leq 0.05$ ). At water activity 0.33 some decrease is observed in parameter $a^{*}$ (redness), with an unexpected increase by the end of storage. An increase in $b^{*}$ (yellowness) and L* (lightness) were also noted along the 145 day storage period; and this was again confirmed by an ANOVA test. Mazza and Francis (1995) reported that during $42{ }^{\circ} \mathrm{C}$ storage of red wine, redness decreased but yellowness increased due to the higher concentration of chalcone; this observation is in agreement with measured increase of parameter $b^{*}$ during accelerated storage of EWP.

In a low moisture system (EWP), $\mathrm{a}_{\mathrm{w}}$ (or moisture content) is a 

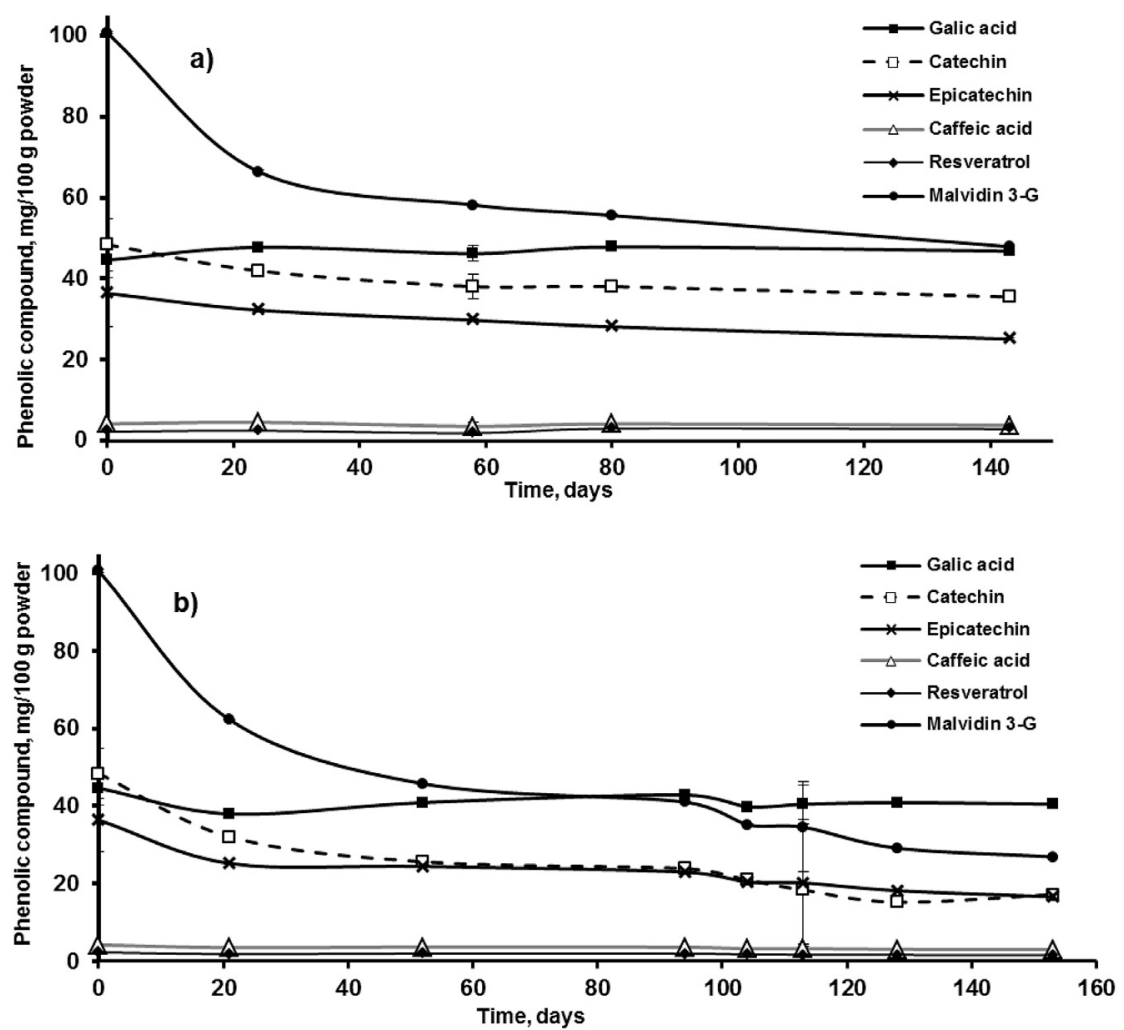

Fig. 4. Evolution of selected phenolics in EWP stored at $38{ }^{\circ} \mathrm{C}$ and different water activities. a) $0.11 \mathrm{a}_{\mathrm{w}}$; b) $0.33 \mathrm{a}_{\mathrm{w}}$. - In many cases SD bars overlap with data points.
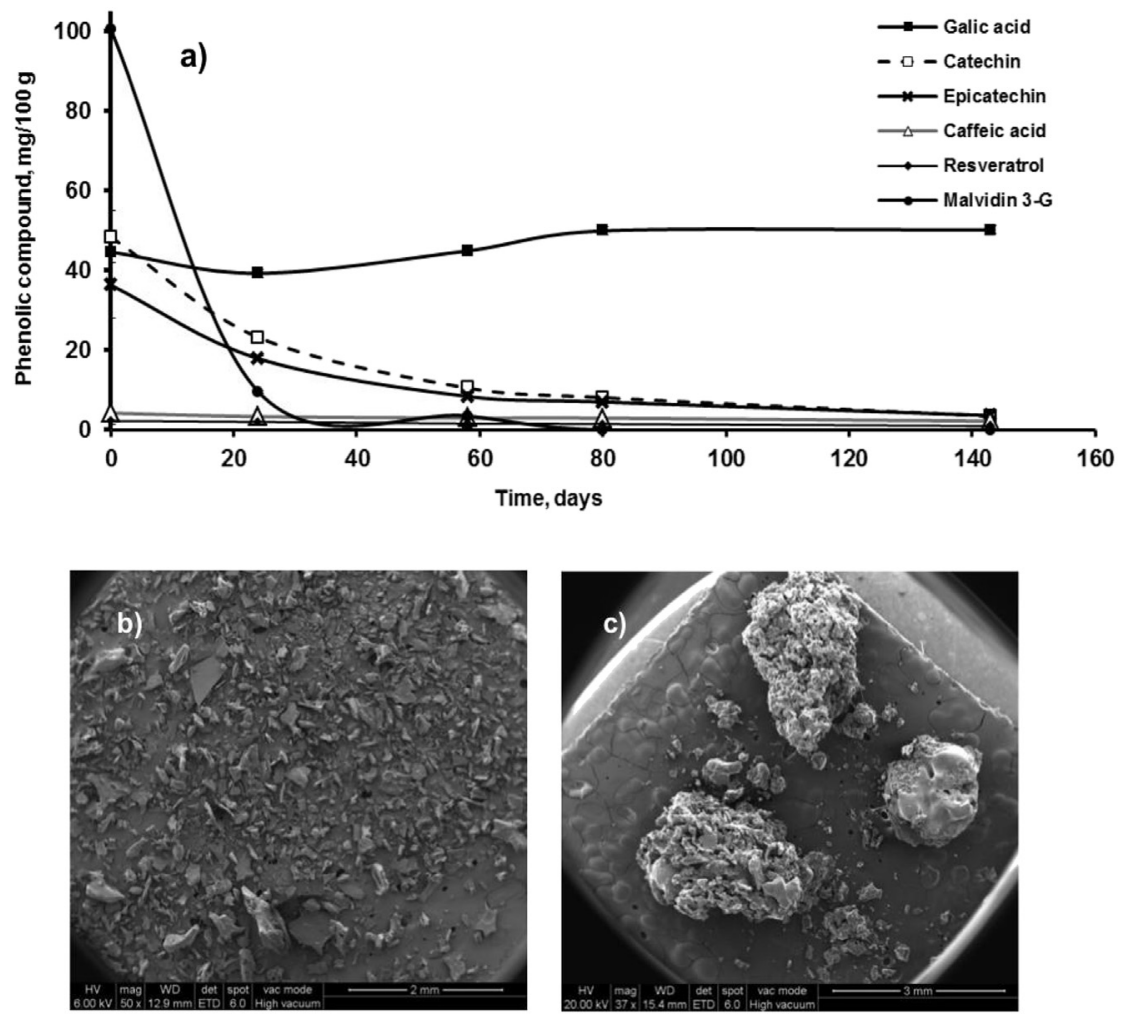

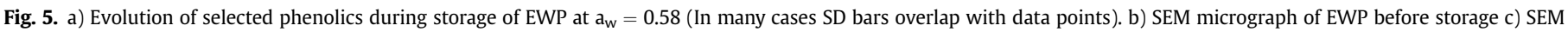
micrograph of caked wine powder after storage at $38{ }^{\circ} \mathrm{C}$ and $0.58 \mathrm{a}_{\mathrm{w}}$ 

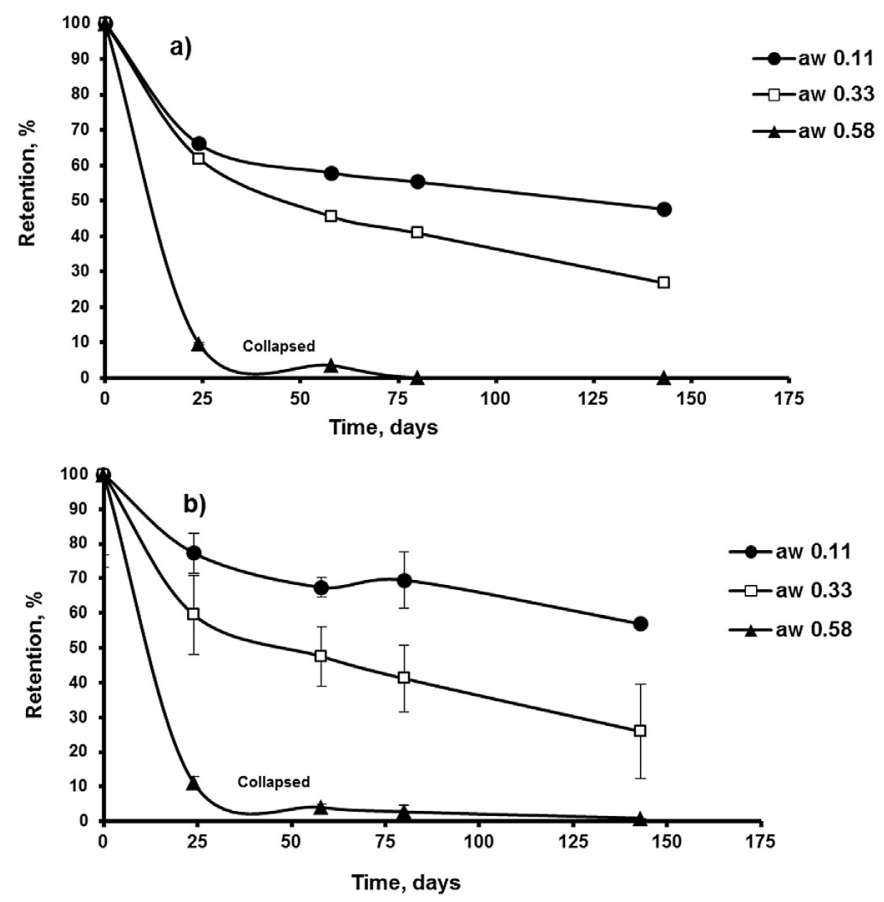

Fig. 6. Effect of water activity on malvidin 3-G (a) and Total anthocyanins (b) during storage at $38{ }^{\circ} \mathrm{C}$ of EWP. - In many cases SD bars overlap with data points.

key factor affecting chemical (and physical) stability. Since water acts as a plasticizer accelerating (or decreasing) chemical reactions by influencing molecular mobility (Buera, Welti-Chanes, Lillford, \& Corti, 2006; Roos, 1995).

Fig. 3 shows the HPLC chromatogram of EWP before and after 145 days at accelerated storage conditions; the peaks of selected phenolic compounds are indicated with arrows on the figure. A qualitative overall view of these peaks anticipates that malvidin 3$\mathrm{G}$ and catechin are the less stable of the selected phenolics. It is to be noted that at $320 \mathrm{~nm}$ and $280 \mathrm{~nm}$ some unidentified peaks appeared in the chromatogram and this will be discussed later in the manuscript.

Fig. 4 (a,b) shows the changes in phenolic contents in EWP stored at $38{ }^{\circ} \mathrm{C}$ and two different water activities (0.11 and 0.33) over 145 days storage. As indicated by an ANOVA test performed over the data ( $\mathrm{p} \leq 0.05)$. Gallic acid, catechine, epicatechine, caffeic acid and resveratrol remained approximately constant throughout storage period at $\mathrm{a}_{\mathrm{w}} \mathbf{0 . 1 1}$. On the contrary, malvidin $3-\mathrm{G}$ showed an important initial decrease followed by a slower one. At a higher $\mathrm{a}_{\mathrm{w}}=0,33$ only gallic acid remained constant. Catechine and epicatechine exhibited an initial decrease but then remained constant up to the end of storage (145 days); their final losses were 65 and $54 \%$ respectively. For the same storage conditions, losses of caffeic acid and resveratrol were 29 and 31\% respectively. Malvidin 3-G showed the largest decrease amounting to about $70 \%$ of its initial value. It is interesting to note that the decrease in malvidin 3-G content is associated with the decrease in redness (colour parameter $\mathrm{a}^{*}$ ) previously noted in Fig. 2 . This behaviour was confirmed by Pearson positive correlation 0.80 ( $\mathrm{p} \leq 0.05$ ). Sanchez, Baeza, and Chirife (2015) also reported that loss of monomeric anthocyanin was associated with a decrease in redness colour (parameter $\mathrm{a}^{*}$ ) in stored encapsulated cherry juice.

Overall, the stability behaviour of selected phenolics is similar to that reported by Galmarini et al. (2013) for same phenolics in red wine but encapsulated with $20 \%$ of maltodextrin instead of $9 \%$ of maltodextrin + gum arabic, as used in the present work. They reported stability data for similar values of water activity and temperature, but during a shorter storage period (70 days). Other authors also reported data on stability of phenolics in low-moisture food powders. For example, Tandale (2007) used whey protein concentrate as carrier material and stored freeze-dried encapsulated gallic acid at $25{ }^{\circ} \mathrm{C}$. It was found to have very good retention (above $90 \%$ ) at aw $=0.22$ and 0.44 after 56 days storage. Tonon et al. (2010) studied anthocyanin stability of spray-dried açai juice produced with different carriers and found that temperature negatively influenced anthocyanin stability and the increase of water activity also resulted in higher degradation. This was attributed to the higher molecular mobility, which allows easier oxygen diffusion, thus accelerating the oxidation reactions.

Fig. 5(a) shows the evolution of selected phenolics during storage of EWP at $\mathrm{a}_{\mathrm{w}}=0.58$ and $38{ }^{\circ} \mathrm{C}$. As mentioned before, at this combination of water activity and temperature the amorphous structure collapsed and caking was observed (see Fig. 5 b,c). This was reflected in a dramatic loss of malvidin 3-G as well as losses of the other phenolics with the exception of gallic acid which remained constant.

Fig. 6 compiles the effect of water activity on the \% retention of malvidin 3-G and total anthocyanins in EWP stored at $38{ }^{\circ} \mathrm{C}$. Increasing the water activity from 0.11 to 0.58 strongly affected the retention of these phenolics and stress the importance of water activity as a control parameter for anthocyanins stability during storage. It is to be noted that the behaviour of malvidin 3-G and total anthocyanins is similar because malvidin $3-G$ is the main phenolic compound of total anthocyanins in red wine (see Fig. 3.).

The "antioxidant power" of a food is an expression of its capability both to defend the human organism from the action of the free radicals and to prevent degenerative disorders deriving from persistent oxidative stress (Di Majo, La Guardia, Giammanco, La Neve, \& Giammanco, 2008). Thus, one of the important characteristics of polyphenolic compounds is their antiradical property.

Fig. 7 shows the evolution of Total Polyphenols (a), Antioxidant capacity determined with chromogen radical $\mathrm{DPPH}^{*}(\mathbf{b})$ and Antioxidant capacity determined by the $\beta$-Carotene/Linoleic acid assay (c), for EWP at accelerated storage conditions Total polyphenols, antioxidant capacity determined with chromogen radical $\mathrm{DPPH}^{*}$ and antioxidant capacity determined by $\beta$-Carotene/Linoleic acid assay remained approximately constant during storage, as determined by ANOVA test performed on the data shown in Fig. 7 a, b,c.

A good correlation between the antioxidant activities (determined by several methods) and total phenol content (Folin Method) has been observed for red wines (Büyüktuncel, Porgall, \& Çolak, 2014; Stratil, Kubáň, \& Fojtová, 2008). However, the relationship between antioxidant capacity and specific phenolic compounds was unclear. Di Majo et al. (2008) indicated that the wine's antioxidant properties of red wines from Sicilia are influenced differently by each polyphenolic molecule. Van Leeuw, Kevers, Pincemail, Defraigne, and Dommes (2014) studied several different wines having large variability in the levels of individual phenolic compounds as well as in antioxidant capacity. Comparisons of the different wines based on their individual phenolic profile and antioxidant capacities (ORAC, DPPH, hemolysis, ESR, and total phenolics) showed limited differences.

As shown before contents of malvidin 3-G, catechin and epicatechin in EWP had an important decrease after 145 days at accelerated storage conditions; however these losses were not reflected in a change of antioxidant capacity. This lack of correlation between loss of some phenolics and antioxidant capacity has been also reported by others authors in different food systems. Kotseridis, Kallithraka, Kyraleou, Proxenina, and Makris (2013) studied the effect of storage on antioxidant capacity of wine and noted that oxidised phenolics may produce the formation of novel 

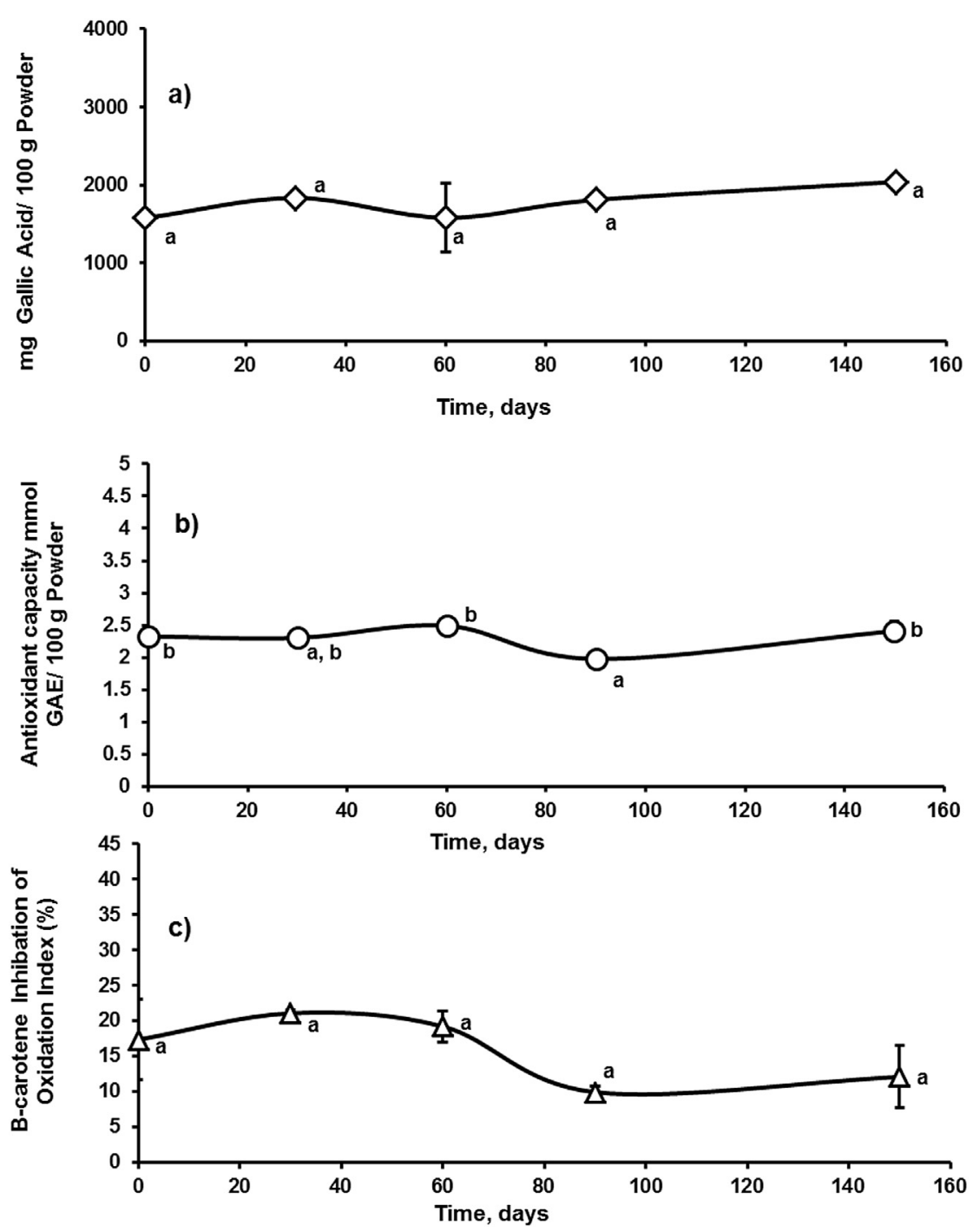

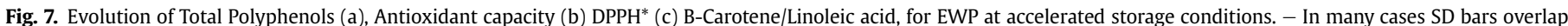
with data points. Different letters denote statistically significant difference at $\mathrm{p}<0.05$.

antioxidants, and an increase in the wine antioxidant status may be observed. Kallithraka, Salacha, and Tzourou (2009) measured antioxidant activity and phenolics content during storage ( 9 months at $15^{\circ} \mathrm{C}$ ) in bottled white wine and measured the concentrations of several phenolics. They found that content of most phenolics diminished with time, but the antioxidant activity increased with storage and stated that although one would expect oxidation of antioxidants to yield a lower antioxidant capacity, reactions between oxidised phenolics may produce formation of new antioxidants. Brownmiller, Howard, and Prior (2008) evaluated the effects of processing and 6 months of storage on total monomeric anthocyanins, percent polymeric colour, and antioxidant capacity of blueberries. Storage at $25{ }^{\circ} \mathrm{C}$ resulted in dramatic losses in total anthocyanins, ranging from $62 \%$ in berries to $85 \%$ in clarified juices. This coincided with marked increases in percent polymeric colour values of these products. However, the antioxidant capacity (ORAC) showed little change during storage, indicating that the formation of polymers compensated for the loss of antioxidant capacity due to anthocyanin degradation.

The observed stability of antioxidant capacity of EWP during storage may be explained by reactions between oxidised phenolic compounds which bring about formation of new antioxidants. As noted before (Fig. 4.) at $280 \mathrm{~nm}$ and $320 \mathrm{~nm}$ some unidentified peaks appeared in the chromatograms which were not present in initial EWP sample, but appeared after accelerated storage. Galmarini et al. (2013) also found that antioxidant capacity of red wine encapsulated with maltodextrin alone remained almost constant after 70 days storage on spite of 33\% loss of malvidin 3-G and also some losses in catechin and epicatechin.

\section{Conclusions}

The addition of a $9 \%$ mixture (65:35) of the encapsulating agents maltodextrin (DE 10) and gum arabic to red wine $C$. sauvignon followed by freeze-drying, allowed to obtain a dealcoholized wine powder having a phenolic concentration 7.1 times higher than the original liquid red wine. The glass transition temperature $\left(\mathrm{T}_{\mathrm{g}}\right)$ permitted the wine powder to remain free flowing avoiding adverse physical changes (i.e. caking) during accelerated storage conditions.

Gallic acid, catechin, epicatechin, caffeic acid and resveratrol remained approximately constant throughout storage period $\left(38{ }^{\circ} \mathrm{C}\right)$ at $\mathrm{a}_{\mathrm{w}} 0.11$; on the contrary malvidin $3-\mathrm{G}$ showed an important initial decrease followed by a slower one. 
At a higher $\mathrm{a}_{\mathrm{w}}=0,33$ only gallic acid remained constant. Catechin and epicatechin exhibited an initial decrease but then remained constant up to the end of accelerated storage (145 days); final losses were 65 and 54\% respectively. Losses of caffeic acid and resveratrol were 29 and 31\% respectively. Malvidin 3-G showed an important decrease amounting to about $70 \%$ of the initial value.

Malvidin 3-G and total anthocyanins were the phenolics that showed greater losses during storage. Increase of water activity from 0.11 to 0.58 enhanced the loss of these phenolics indicating that water activity (or moisture content) is a key factor affecting the stability of these compounds during storage.

Antioxidant activity of the wine powder exhibited a good stability over 145 days at accelerated storage conditions. In spite of some phenolic losses the antioxidant capacity of EWP remained constant and this may be explained by reactions between oxidised phenolic compounds which may bring about formation of new antioxidants.

Due to its high polyphenols content (7.1 times the original wine) the wine powder may be used for polyphenol enrichment of healthy powder drinks; also its encapsulation technique may provide protection to phenolics against conditions such as oxidation.

\section{Acknowledgements}

The present work was financed by PREMIO NACIONAL ARCOR A LA INNOVACION EN ALIMENTOS - EDICION 2013.

\section{References}

Brouillard, R., George, F., \& Fougerousse, A. (1997). Polyphenols produced during red wine ageing. BioFactors (Oxford, England), 6, 403-410.

Brownmiller, C., Howard, L. R., \& Prior, R. L. (2008). Processing and storage effects on monomeric anthocyanins, percent polymeric color, and antioxidant capacity of processed blueberry products. Journal of Food Science, 73(5), H72-H79.

Buera, M. P., Welti-Chanes, J., Lillford, P., \& Corti, H. R. (2006). Water properties of food, pharmaceutical and biological materials. United States of America: CRC, Taylor \& Francis.

Büyüktuncel, E., Porgalı, E., \& Çolak, C. (2014). Comparison of total phenolic content and total antioxidant activity in local red wines determined by spectrophotometric methods. Food and Nutrition Sciences, 5(5), 1660-1667.

Camussoni, G., \& Carnevali, E. (2004). Determinación comparativa del contenido de polifenoles en vinos tintos de origen Argentino. INVENIO, 151-159.

De Souza, V. B., Thomazini, M., Balieiro, J. C. D. C., \& Favaro-Trindade, C. S. (2015). Effect of spray drying on the physicochemical properties and color stability of the powdered pigment obtained from vinification byproducts of the Bordo grape (Vitis labrusca). Food and Bioproducts Processing, 93, 39-50 (October).

Deyse Gurak, P., Correa, M. L., \& Rocha-Leão, M. H. (2013). Production of grape juice powder obtained by freeze- drying after concentration by reverse osmosis. Archives of Biology and Technology, 56656(6), 1011-1017.

Di Majo, D., La Guardia, M., Giammanco, S., La Neve, L., \& Giammanco, M. (2008). The antioxidant capacity of red wine in relationship with its polyphenolic constituents. Food Chemistry, 111(1), 45-49.

Ferrari, C. C., Marconi Germer, S. P., Alvim, I. D., \& de Aguirre, J. M. (2013). Storage stability of spray-dried blackberry powder produced with maltodextrin or gum arabic. Drying Technology, 31(4), 470-478.

Galmarini, M. V., Maury, C., Mehinagic, E., Sanchez, V., Baeza, R. I., Mignot, S., et al.
(2013). Stability of individual phenolic compounds and antioxidant activity during storage of a red wine powder. Food and Bioprocess Technology, 6(Ldl), 3585-3595.

Iglesias, H. A., \& Chirife, J. (1982). Handbook of food isotherms: Water sorption parameters for food and food components. ACADEMIC PRESS, INC.

Kallithraka, S., Salacha, M. I., \& Tzourou, I. (2009). Changes in phenolic composition and antioxidant activity of white wine during bottle storage: accelerated browning test versus bottle storage. Food Chemistry, 113(2), 500-505.

Kotseridis, Y., Kallithraka, S., Kyraleou, M., Proxenina, N., \& Makris, D. P. (2013). Browning rate of white wines: dependence on antioxidant activity kinetics and changes in phenolic composition. In 3rd international symposium ampelos 2013, trends in world vitiviniculture development.

Li, H., Wang, X., Li, Y., Li, P., \& Wang, H. (2009). Polyphenolic compounds and antioxidant properties of selected China wines. Food Chemistry, 112(2), 454-460.

Lu, Y., \& Foo, L. Y. (2000). Antioxidant and radical scavenging activities of polyphenols from apple pomace. Food Chemistry, 68, 81-84.

Mahdavi, S. A., Jafari, S. M., Ghorbani, M., \& Assadpoor, E. (2014). Spray-drying microencapsulation of anthocyanins by natural biopolymers: a review. Drying Technology, 32(5), 509-518.

Mazza, G., \& Francis, F. J. (1995). Anthocyanins in grapes and grape products. Critica Reviews in Food Science and Nutrition, 35(4), 341-371. http://doi.org/10.1097/NT 0b013e31823db374.

Midgley, J. (1971). Drinking and attitude toward drink in a Muslim community. Quarterly Journal of Studies on Alcohol, 32, 148-158.

Munin, A., \& Edwards-Lévy, F. (2011). Encapsulation of natural polyphenolic compounds; a review. Pharmaceutics, 3.

Parra, D. R., Galmarini, M., Chirife, J., \& Zamora, M. C. (2015). Influence of information, gender and emotional status for detecting small differences in the acceptance of a new healthy beverage. Food Research International, 76, 269-276.

Roos, Y. H. (1995). Phase transitions in foods. Elsevier. http://doi.org/10.1016/B978012595340-5/50000-6.

Roos, Y., \& Karel, M. (1991). Phase-transitions of mixtures of amorphous polysaccharides and sugars. Biotechnology Progress, 7(1), 49-53.

Sanchez, V., Baeza, R., \& Chirife, J. (2015). Comparison of monomeric anthocyanins and colour stability of fresh, concentrate and freeze-dried encapsulated cherry juice stored at $38{ }^{\circ} \mathrm{C}$. Journal of Berry Research, 5(4), 243-251.

Sanchez, V., Baeza, R., Galmarini, M. V., Zamora, M. C., \& Chirife, J. (2013). Freezedrying encapsulation of red wine polyphenols in an amorphous matrix of maltodextrin. Food and Bioprocess Technology, 6(5), 1350-1354.

Souquet, J.-M., Veran, F., Mané, C., \& Cheynier, V. (2006). Optimization of extraction conditions on phenolic yields from the different parts of grape clusters. Quantitative distribution of their proanthocyanidins. In XXIII internationa conference on polyphe nols winipeg (Manitoba, Canada) (pp. 245-246).

Stratil, P., Klejdus, B., \& Kuban, V. (2006). Determination of total content of phenolic compounds and their antioxidant activity in vegetables s evaluation of spectrophotometric methods. Journal of Agricultural and Food Chemistry, 54, 607-616.

Stratil, P., Kubán̆, V., \& Fojtová, J. (2008). Comparison of the phenolic content and total antioxidant activity in wines as determined by spectrophotometric methods. Czech Journal of Food Sciences, 26(4), 242-253.

Tandale, S. R. (2007). Microencapsulation of vitamin c and gallic acid in whey protein concentrate by spray and freeze drying characterization and degradation kinetics (Ph.D. thesis). Athens, GA: Graduate Faculty of the University of Georgia.

Tedesco, I., Russo, M., Russo, P., Iacomino, G., Russo, G. L., Carraturo, A., et al. (2000). Antioxidant effect of red wine polyphenols on red blood cells. The Journal of Nutritional Biochemistry, 11(2), 114-119.

Tonon, R. V., Brabet, C., \& Hubinger, M. D. (2010). Anthocyanin stability and antioxidant activity of spray-dried açai (Euterpe oleracea Mart.) juice produced with different carrier agents. Food Research International, 43(3), 907-914.

Van Leeuw, R., Kevers, C., Pincemail, J., Defraigne, J. O., \& Dommes, J. (2014). Antioxidant capacity and phenolic composition of red wines from various grape varieties: specificity of Pinot Noir. Journal of Food Composition and Analysis, 36 40-50. 